\title{
Pyricularia oryzae en cultivos de cebada en Corrientes (Argentina)
}

\author{
Susana Alejandra Gutiérrez y María Agueda Cúndom
}

Cátedra de Fitopatología, Facultad de Ciencias Agrarias, Universidad Nacional del Nordeste, Sargento Cabral 2131, 3400, Corrientes, Argentina Autor para correspondencia (sualejandra@hotmail.com)

Data de chegada: 26/11/2014. Aceito para publicação em: 07/07/2015.

$10.1590 / 0100-5405 / 2063$

\section{RESUMEN}

Gutiérrez, S.A.; Cúndom, M.A. Pyricularia oryzae en cultivos de cebada en Corrientes (Argentina). Summa Phytopathologica, v.41, n.4, p.318$320,2015$.

Durante la campaña 2012-2013, en cultivos de cebada forrajera (Hordeum vulgare var. Alicia INTA), se observaron síntomas de tizón foliar. El agente causal (Pyricularia oryzae) fue identificado según características morfométricas, culturales y de patogenicidad. Constituye ésta la primera información del patógeno para cultivos de cebada forrajera en Argentina.

Palabras claves: Hordeum vulgare, hongo, tizón foliar.

\section{RESUMO}

Cabezas S.R.M.; Silva, G.S. Pyricularia oryzae em cultivos de cevada na região de Corrientes (Argentina). Summa Phytopathologica, v.41, n.4, p.318-320, 2015.

Durante os anos 2012-2013, em culturas de cevada (Hordeum vulgare var. Alicia INTA), foram observados sintomas de crestamento foliar. O agente causal (Pyricularia oryzae) foi identificado según do características culturais, morfológicas e patogênicas. Constitui o primeira relato do patógeno para as culturas de cevada em Argentina.

Palavras-chave: Hordeum vulgare, fungo, crestamento foliar.

\section{ABSTRACT}

Cabezas S.R.M.; Silva, G.S. Pyricularia oryzae affecting barley crops in Corrientes (Argentina). Summa Phytopathologica, v.41, n.4, p.318-320, 2015.

During 2012-2013, in barley (Hordeum vulgare var. Alicia INTA) plants, leaf blight symptoms were observed. The causal agent (Pyricularia oryzae) was identified based on cultural, morphological and pathogenic characteristics. This is the first report of the pathogen for barley crops in Argentina.

Keywords: Hordeum vulgare, fungus, leaf blight

En los últimos años, los sistemas ganaderos de la provincia de Corrientes (Argentina) pasaron de sistemas exclusivamente de cría a sistemas de cría y recría o incluso de ciclo completo. Este nuevo escenario requiere del incremento en la producción de forraje, mediante la introducción de pasturas perennes y verdeos de invierno, para cubrir el periodo invernal, que es el principal problema en la cadena forrajera en el nordeste argentino. Actualmente, las principales pasturas utilizadas son raygrass (Lolium perenne) y avena (Avena sativa, A. bizantina). El cultivo de la cebada forrajera (Hordeum vulgare L.) se presenta como una posible alternativa a ser incluida durante el invierno (1).

Durante la campaña agrícola 2012-2013, en monitoreos de cultivos de cebada forrajera var. Alicia INTA, ubicados en la localidad de Mercedes (Corrientes, Argentina), se observaron plantas enfermas con síntomas de tizón foliar los que se manifestaron a partir del estadio de macollaje y se intensificaron hacia la madurez del mismo, con desarrollo inicialmente de manchas alargadas a elípticas, con centro gris verdoso y borde más oscuro, rodeadas de un halo amarillento. En plantas en estados reproductivos, las lesiones foliares se unieron ocasionando necrosis y muerte de gran parte de la lámina foliar (Fig. 1a,b). Se recolectaron hojas enfermas, que se examinaron a simple vista y con microscopio estereoscópico $(90 \mathrm{x})$, a fin de determinar su etiología.

En observaciones preliminares, el agente causal de la enfermedad, se identificó como Pyricularia oryzae. Luego se efectuaron siembras comunes, de trocitos de hojas tomadas del límite entre tejido sano y enfermo, los que se desinfectaron en hipoclorito de sodio al 2,5\% durante un minuto, transfiriéndolos a cajas de Petri con agar papa glucosado (APG) al 1,5\%, acidificado. Las colonias desarrollaron bajo campana de iluminación $12 \mathrm{~h}$ luz - $12 \mathrm{~h}$ oscuridad. Las características morfométricas del hongo identificado, se realizaron en substrato natural y en los aislamientos obtenidos; las características culturales se determinaron en APG. Se identificó al hongo Pyricularia oryzae Cavara (teleomorfo Magnaporthe oryzae B. Couch), cuyas características 

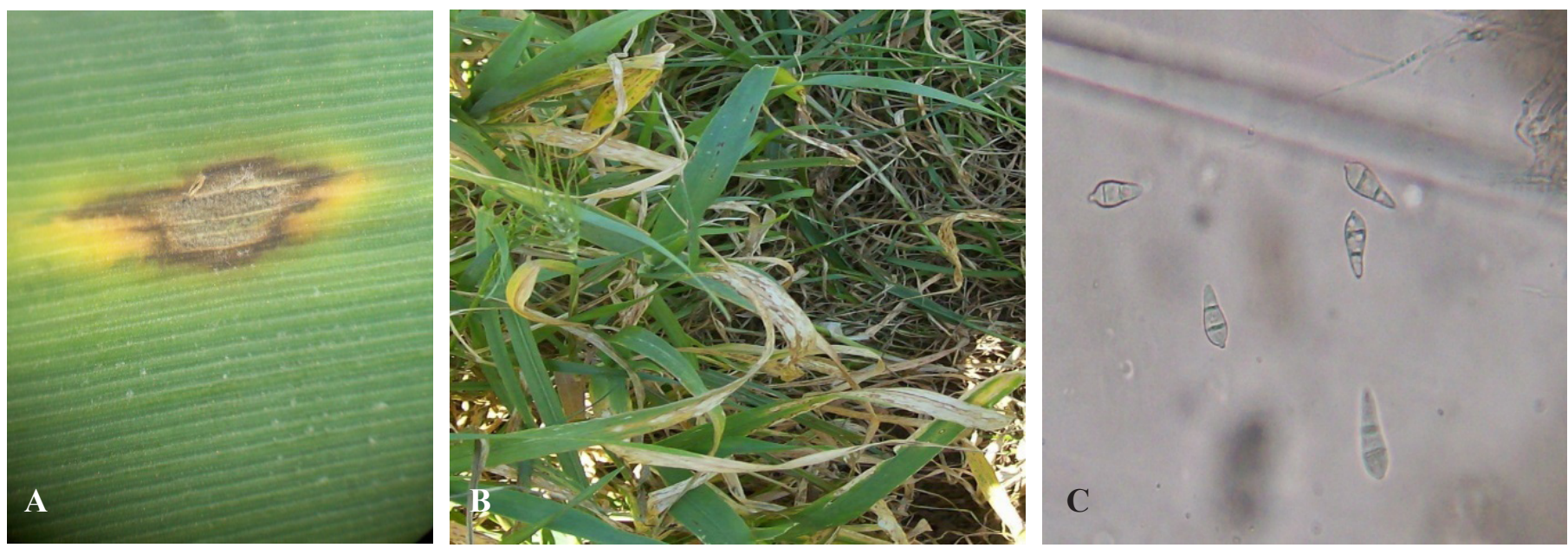

Figura 1: A,B. Síntomas en láminas foliares de cebada forrajeras, C. Conidios de Pyricularia oryzae.

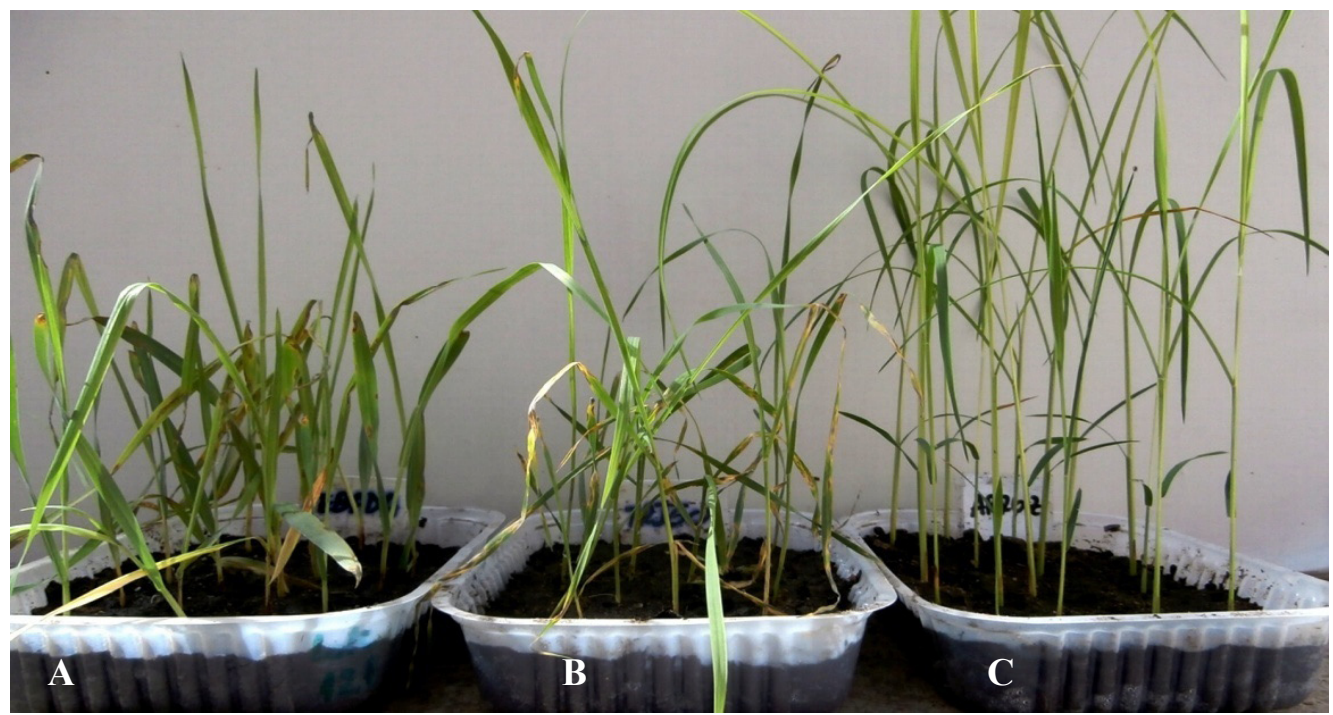

Figura 2. Síntomas de inoculaciones de $P$. oryzae en cebada (A), trigo (B) y arroz (C).

morfométricas y culturales coincidieron con las existentes en la bibliografía $(2,7,8,10)$. El patógeno forma conidióforos simples, que llevan conidios hialinos, piriformes a obclavulados, con 2 septos, de 25,5-32 x 8,5-12,5 $\mu$ (Fig. 1c). Para las pruebas de patogenicidad, se utilizó un aislamiento del hongo inoculando plántulas de cebada forrajera, trigo (Triticum aestivum L.) y arroz (Oryza sativa var. Puitá INTA CL), de 17-20 días de edad, bajo condiciones de invernáculo $\left(25 \pm 2^{\circ} \mathrm{C}\right)$, las que se pulverizaron con una suspensión de conidios del hongo; se llevaron los testigos correspondientes los cuales se pulverizaron con agua estéril.

En las plántulas inoculadas de cebada forrajera y trigo, se observaron síntomas a los 7-8 días posteriores a la inoculación, similares a los detectados en condiciones de campo. Se logró el reaislamiento del patógeno a partir de los tejidos enfermos. En plántulas de arroz, las pruebas de patogenicidad fueron negativas (Fig. 2).

La presencia de $P$. oryzae fue informada en más de 50 gramíneas, incluyendo cereales como arroz, trigo, cebada, avena, maíz, etc, causando pérdidas significativas en algunas regiones productoras bajo condiciones ambientales específicas. También fue identificado en especies forrajeras y numerosas malezas $(2,3,7)$.

En Brasil, Goulart et al, (2003), detectaron la presencia de $P$. oryzae en semillas de cebada, mientras que Lima y Minella (2003), lo observaron asociado a espigas de cebada.

En la provincia de Corrientes, $P$. oryzae afecta principalmente al arroz, además a otras gramíneas (Brachiaria extensa, Bromus catharticus, Digitaria sanguinalis, Echinochloa colonum, Leersia hexandra, Luziola peruviana, Paspalum acuminatum, Panicum dichotomiflorum, Pennisetum purpureum, Stenotaphrum secundatum y Setaria glauca) (5).

Con respecto a la patogenicidad, los resultados obtenidos son coincidentes con los de la bibliografía en la que se demuestra que aislamientos de Pyricularia obtenidos de cebada pueden causar síntomas en plantas de trigo, pero no en arroz $(2,9)$.

Esta la primera información de $P$. oryzae en cultivos de cebada forrajera en Argentina.

\section{REFERÊNCIAS BIBLIOGRÁFICAS}

1. Borrajo, C. I., Barbera, P., Bendersky, D., Pizzio, R., Ramírez M., Maidana, C., Zapata, P., Ramírez, R., Fernández, J.R. Verdeos de invierno en Corrientes. Serie Técnica n ${ }^{\circ} 49$. Ed. Estación Experimental Agropecuaria Mercedes, Corrientes. 22p. 2011. 
2. Couch, B.C., Kohn, L. M. A multilocus gene genealogy concordant with host preference indicates segregation of a new species, Magnaporthe oryzae, from M. grisea. Mycologia v. 94, n. 4, p. 683-693, 2002.

3. Ellis, M.B. Dematiaceous Hyphomycetes, Kew, Surrey, England, Commonwealth. $1971.608 \mathrm{p}$

4. Goulart, A.P., Amabili, R.F., Nasser, L.C.B., Freitas, M.A. Detecção de Pyricularia grisea em sementes de cevada produzidas em sistema irrigado por pivô central no cerrado brasileiro. Fitopatol. bras. v. 28, n. 5, p. 566, 2003.

5. Gutiérrez, S.A., Mazzanti de Castañón, M.A., Galmarini, M.R. 2000. Avanキ ces en el conocimiento de hospedantes espontáneos de Pyricularia grisea en la Argentina. En: Actas de la Reunión de Comunicaciones Científicas y Tecnológicas, SGCYT, UNNE. (http://www.unne.edu.ar).
6. Lima, M.I.P.M., Minella, E.M.I.P.M. Occurrence of head blast in barley. Fitopatol. bras. v.28, n. 2, p.207, 2003.

7. Ou, S.H. Rice diseases. 2nd. ed., Kew, Surrey, England, Commonwealth Mycological Institute. 1985. $380 \mathrm{p}$.

8. Prabhu, A.S., Corsi de Filippi, M.C. eds. Brusone em arroz: controle genético, progresso e perpectivas. Embrapa Arroz e Feijão Santo Antonio de Goiás, GO. 2006. 387 p.

9. Prabhu, A.S., Filippi, M.C., Castro, N. Pathogenic variation among isolates of Pyricularia grisea infecting rice, wheat, and grasses in Brazil. Tropical Pest Management v.38, p. 367-371, 1992.

10. Tosa, P., Chuma, I. Classification and parasitic specialization of blast fungi. Gen. Plant Pathol. v. 80, p. 202-209, 2014. 